\title{
RETIREMENT MIGRATION: THE MALAYSIA MY SECOND HOME (MM2H) PROGRAM AND THE JAPANESE RETIREES IN PENANG
}

\author{
Benny Teh Cheng Guan* \\ School of Social Sciences, Universiti Sains Malaysia, \\ 11800 USM Pulau Pinang, Malaysia \\ E-mail: ben@usm.my
}

Published online: 15 January 2018

To cite this article: Teh, B. C. G. 2018. Retirement migration: The Malaysia My Second Home (MM2H) program and the Japanese retirees in Penang. International Journal of Asia Pacific Studies 14 (1): 79-106, https://doi.org/10.21315/ijaps2018.14.1.4

To link to this article: https://doi.org/10.21315/ijaps2018.14.1.4

\begin{abstract}
Modernisation and easy connectivity across spatial boundaries are providing greater opportunities for retirees to migrate abroad. In Malaysia, the Malaysia My Second Home (MM2H) program has been gaining popularity over the last 14 years. It is a government initiative designed to promote the country as a retirement haven for affluent foreigners. By studying the Japanese retirement community in Penang, this paper examines the role and significance of the program in supporting retirement migration. It further identifies the concerns and contributions of the Japanese retirees as they build their "second lives" in Penang. While the MM2H program has undergone several enhancements, discussions on the experiences of the Japanese participants and research observations have highlighted several concerns that require further improvements. The lack of policy coordination between the various sectors catering to the expanding needs of foreign retirees, for example, reduces the chances of maximising participants' contribution to the local economy. The ability to track and monitor the movement of participants is equally, if not more, important as promoting and enticing new ones.
\end{abstract}

Keywords: Retirement migration, Malaysia My Second Home, MM2H, Japanese retirees, Penang 


\section{INTRODUCTION}

Rapid urbanisation coupled with continuous economic globalisation has led to increased modernity across various parts of the world. Technological innovations and cheaper transportations, particularly of budget airlines, are shrinking time and space and reducing physical boundaries that have separated people and nations for centuries. This naturally contributes to the creation of transnational communities as migration intensifies (Castles 2002). Geographical knowledges and perhaps creolisation caused by the ingress of foreign cultures, particularly of food choices, further transforms cities into cosmopolitan enclaves (see Hannerz 1992; Friedman 1995; Cook and Crang 1996; Rohlen 2002).

Penang has a rich history in cultural cosmopolitanism, not only because it served as a colony of the British Empire but it was a significant entrepot that witnessed the fusion of diverse identities (Loh 2009). Malaysia's involvement and integration in the world economy has further propelled the growth of its cities and improved the quality of living of its people. Vibrant Malaysian cities like Penang and Kuala Lumpur should have joined their Asian and Western counterparts as attractive places to live in. Yet, it is absent from international rankings such as Mercer's 2016 quality of living survey, which showed that only two Asian countries (Singapore and Japan) made the list of 50 top cities in the world (Mercer 2016). ${ }^{1}$ The ECA International's survey of the world's most expensive cities ranked Georgetown (Penang) at 231st compared to Zurich (3rd), Geneva (4th), Beijing (9th), Seoul (10th), Oslo (11th), Tokyo (16th), Singapore (19th), and Yokohama (28th) (ECA International 2015). These surveys indicate that well developed cities provide the best quality of living. Such expensive cities would charm expatriates with flamboyant lifestyles but for retired migrants, the cost of living including affordable housing is a more essential concern.

Hence, surveys that factor in the cost of living apart from health, safety and other concerns would be more appropriate and real. This is where Malaysia becomes attractive and helps explain why Japanese retirees migrate despite having some of the best cities at home. Various retirement migration studies have shown that cost of living is an important factor affecting decisions to migrate (see Longino and Smith 1991; Haas and Serow 1993; King, Warnes and Williams 2000; Rodriguez, Fernandez-Mayoralas and Rojo 2004). It is not merely a push factor but also a pull factor (Haas and Serow 1993) that is often used by the tourism sector as a promotional tool. As the pace of life slows down, elderly migrants may seek to move away from highly urbanised and 
fast paced lifestyles into smaller towns, the countryside and even the coastal areas with natural amenities to enjoy the quieter and more peaceful ambiances (see Gurran 2008; Murakami, Gilroy and Atterton 2009).

While Malaysia, as a developing country, may not have cities capable of competing with other countries' well developed cosmopolitan cities as reflected in the rankings surveyed by Mercer and the ECA International, it is bestowed with factors favourable for the development of retirement migration in the country. The rapid increase in the aging population worldwide provide invaluable opportunities for Malaysia to focus on this particular segment of migration by wooing retirees from developed nations and providing them with the standard of living that they seek for. Their presence would contribute to the growth of the local economy. To do so would require effective policies and coordination as well as support from multitude of actors ranging from the highest level of government to those in tour agencies, hospitals, real estates and the renovation businesses.

Government policies on retirement migration plays a crucial role not only in addressing immigration issues that blocks international mobility but also the perks or benefits that entice retired migrants to stay long term. In Malaysia, the Malaysia My Second Home (MM2H) program is at the centre of a government-led effort to bring in more qualified long-term stayers. The paper asks: What policies have the government put in place in developing the country as the preferred destination for retired migrants? What administrative issues have the government faced and subsequent policy changes offered over the course of time? The paper further looks at the participation of Japanese retirees and their lifestyles to better understand the significance and challenges of the program. Although they are now statistically the second largest participating group behind China, there is a rich history between their participation in the program and the evolution of the program itself. They were the key targets when the program started and their support to the program, particularly for the age group 50 years and above, have remained steadfast even as the program evolved beyond its original intention.

This paper is divided into four interlocking sections. The first section provides an outline of where Malaysia stands in the area of retirement migration and a brief historical account of the Japanese community in Penang. The second section provides an in-depth understanding of the motivation behind the MM2H program and discusses the policy changes and issues that have occurred over time. The third section seeks to identify the pull and push factors that have encouraged Japanese retirees to choose Penang as their desired location and explain the social networks and support system that they require 
in carrying out their daily lives and building social goodwill with the local residents. The last section summarises the discussion with an evaluation on the MM2H program and issues pertaining to Japanese participants' contributions.

\section{RETIREMENT MIGRATION AND THE JAPANESE COMMUNITY}

Malaysia has been continuously listed favourably in international retirement surveys. The International Living magazine that provides information on how to live a more fulfilling life offshore at a lower cost ranked Malaysia at 19th placing in 2010 but jumped to 4th place out of 19 best countries to retire in its 2011 global retirement index. In 2016, Malaysia remained at fifth place out of 23 countries (see Table 1; International Living 2016). The survey offers a very different set of countries when a range of key indicators from real estate and government provisions to healthcare and weather are taken into consideration. These indicators eliminate expensive developed nations like Japan, Austria, Switzerland and even Singapore, featuring middle to upper middle income countries instead.

In another ranking, Kathleen Peddicord of Live and Invest Overseas came up with a closely similar list of countries naming Malaysia, Thailand and Vietnam as the only Asian countries to make the top 18 destinations (others in the Americas and Europe) for Americans to retire (New Straits Times 2012). In 2013, Georgetown (Penang) was named by Live and Invest Overseas as the top four best places to retire out of 21 destinations in the world (The Huffington Post 2013). While these surveys may establish Malaysia as an international retirement haven, it says little, if any, of the destination preferences for Japanese retirees.

The Japanese government has been encouraging Japanese retirees to live abroad since 1986 and the idea was, according to Toyota and Ono, inspired by "foreign retirement communities in Spain" (2012: 168). The Long Stay Foundation (LSF), a public corporation under the Japanese Ministry of Economy, Trade and Industry (METI), has been carrying out annual surveys on Japanese interested to live abroad. It terms them as "long-stayers"- those who go abroad to live (rather than to travel) for a long period (defined as more than two weeks) with an intention to return to Japan. Its 2009 survey found that, under the age group of 40 years and above, those who chose Malaysia (2086 people) outweigh those who chose Australia (1157), Thailand (1102), Hawaii (1032), New Zealand (871) and other countries as their preferred destination 
(LSF, 2009: 7). ${ }^{2}$ Table 2 shows the preferences of the Japanese in their choice of destination with Malaysia continuing to remain as the most favoured.

Why is Malaysia a top choice for Japanese retirees? Megumi Ono found in her studies that Japanese retirees enrolling themselves in the MM2H program chose Malaysia for its "low cost of living, good climate and geography, a good living environment, efficient visa systems, availability of care for the elderly, satisfaction from ikigai (reason for living) activities and the existence of Japanese communities" (2008: 157). Associations such as the Japan Club in Kuala Lumpur provide opportunities for retirees to socialise, settle in to their new environment, and stay energetic through various planned activities (Shakuto-Neoh 2014). Wong and Musa (2014 and 2015) concur with Ono but expanded the list to include other factors such as political stability, meaningful second life, ease of communication and friendly people. In addition to the above, the LSF views active promotions of Malaysia and the MM2H program carried out by the Malaysia Tourism Promotion Board as an equally important factor in influencing the retirees' preference (personal comm. January 2017).

Two common terms used in migration studies are "long stay tourism" and "lifestyle migration." The former fits the notion of people who travels to a particular foreign land initially under a tourist visa and ended up settling there for a long period of time but without the intention to gain permanent residency or citizenship. Studies by Hongsranagon (2005 and 2006) and Ono (2008) utilise this term to explain retirement migration of the Japanese. The latter, write O'Reilly and Benson, is "about escape, escape from somewhere and something, while simultaneously an escape to self-fulfilment and a new life" (2009: 3). This term has been actively employed to explain the influx of Japanese migrants in Australia (Sato 2001; Nagatomo 2009), the privileged Western expatriates living in Indonesia (Fechter 2007) and the affluent foreigners converging in rural areas in New Zealand (Fountain and Hall 2002). In short, it is to enjoy a better way of life whether for spiritual or material gains. For the purpose of this paper, retirement migration incorporates the elements of these two terms and is understood as the movement of Japanese retirees into Malaysia under the MM2H program with the objective to start a new life and stay long term. 


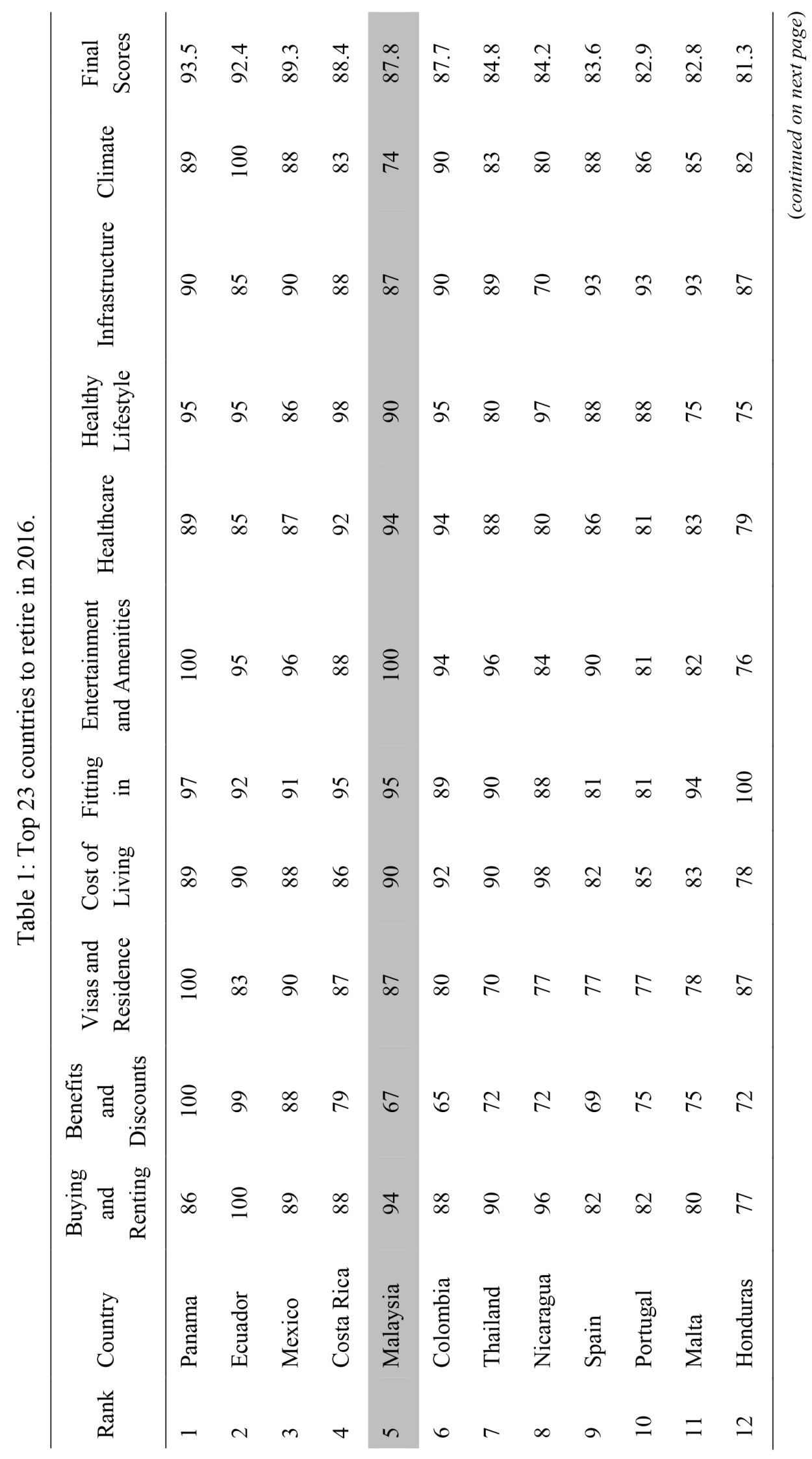




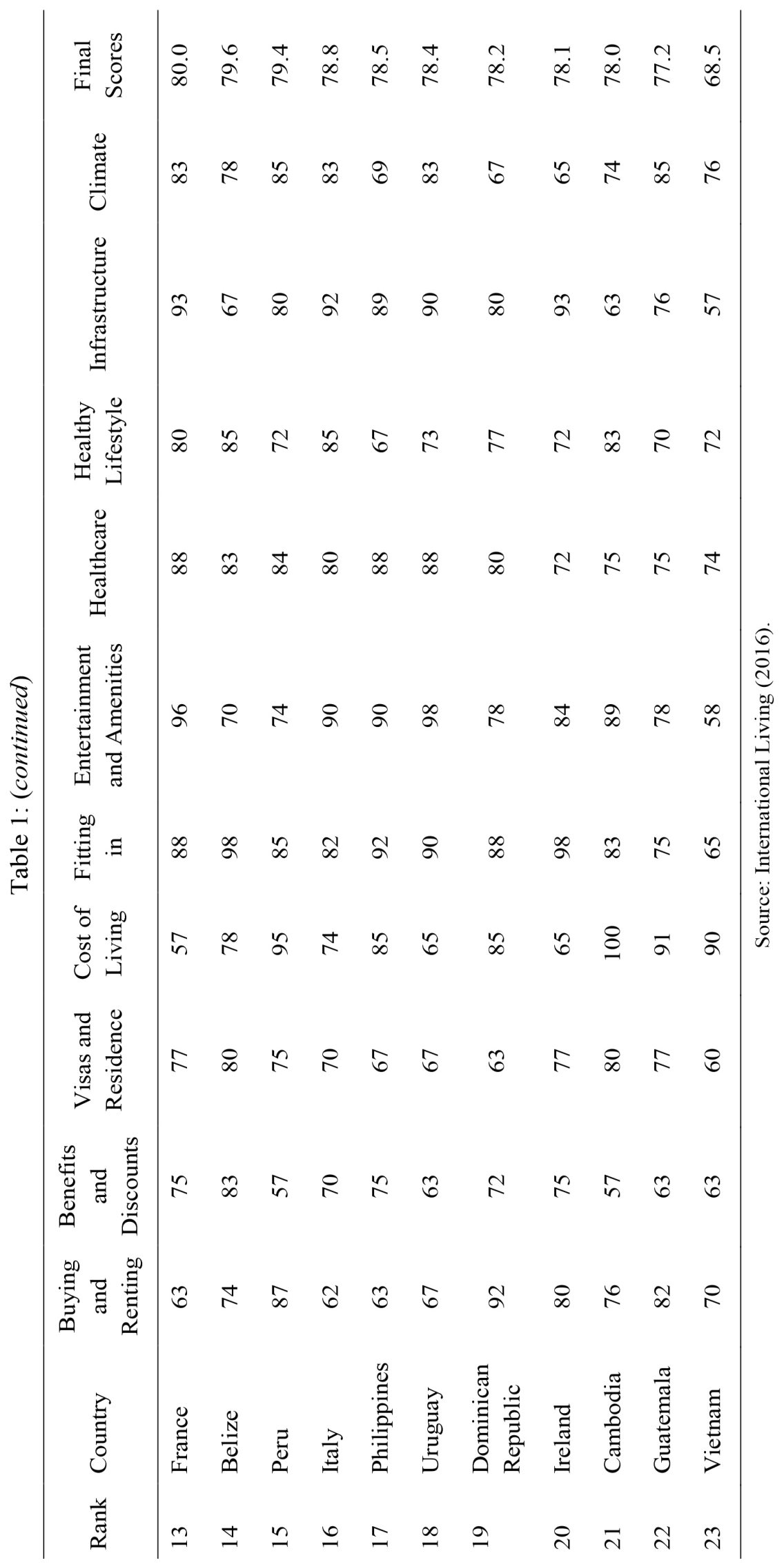




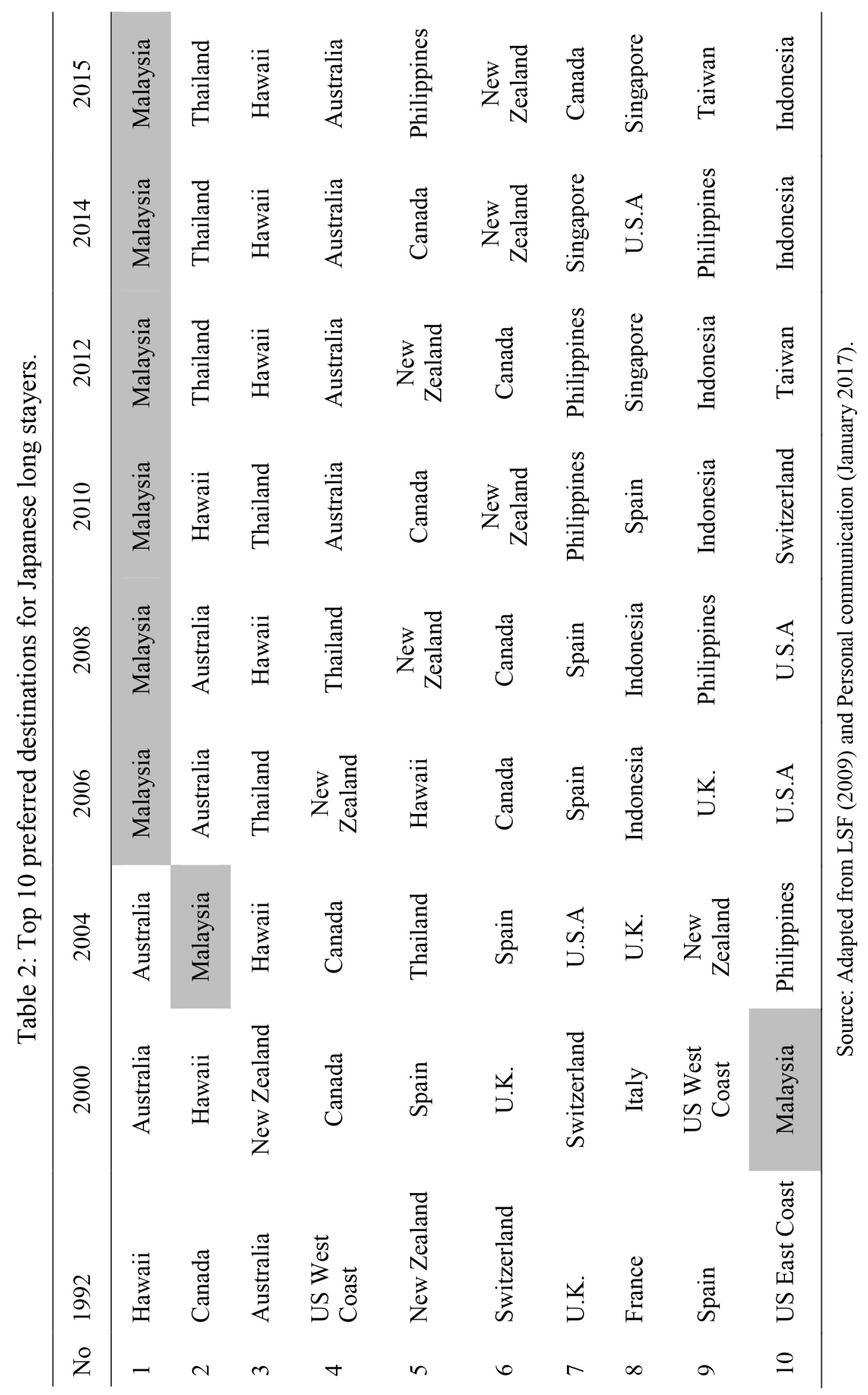




\section{The Japanese Community in Penang}

The Japanese community in Penang can be traced back to the late 19th century. During the Meiji era, "Malaya was a refuge for vagabond sailors and a dumping ground for enslaved prostitutes from Japan" (Yuen 1978: 163). Female migrants outnumbered males with prostitution being the major business as it was a legal trade in the Malay Peninsular until 1920 (Shimizu 1993: 66). The brothel activities in colonial Penang spawned a host of supportive businesses from photo studios, hair salons and grocery shops to hotels, dentistry and pharmacies run by the Japanese community (Liang 2002). ${ }^{3}$ The small but spirited community was well engaged with the locals and "they brought in new ideas and modern equipment to Penang" (Liang 2002: 10). The Japanese Charity and Youth Club was set up to foster togetherness and enhance their social welfare before a more formal Japanese Association was established in 1915 to represent their needs and interests (Liang 2002: 8). From 1920 until the outbreak of the Second World War, male migrants increased while females dropped drastically and commerce shifted towards trading (cheap product imports from Japan) and agriculture (rubber plantation) (Shimizu 1993; Liang 2002).

Penang began to see the development of a new Japanese community made up mainly of white-collar expatriates from the 1970s onwards when it embarked on an export oriented industrialisation process and opened its doors to foreign direct investments. This process encouraged Japanese multinational corporations engaged in manufacturing and trading industries to invest in Penang. The steady increase in the Japanese populace led to the formation of the Penang Japanese Association in 1978 to look after their wellbeing. The subsequent introduction of Malaysia's Look East Policy (LEP) in 1982 and events following the 1985 Plaza Accord further accelerated Penang's growth and thereby their population. ${ }^{4}$ If the pre-war Japanese community is considered as economic migrants, the present community can be considered as lifestyle migrants as they are better educated and highly skilled.

There are about 2,000 Japanese currently living in Penang with an estimated figure of about 500 of them as retired migrants under the MM2H program (The Star 2006). With a long historical involvement of the Japanese community in the socio-economic development of Penang and their experiences in living and working there, it can only be expected that more will choose Penang as their second home. Before discussing further on Japanese retirees in Penang, it is necessary to illustrate the role and development of the $\mathrm{MM} 2 \mathrm{H}$ program in relation to retirement migration. 


\section{THE MM2H PROGRAM}

The MM2H program (henceforth MM2H) is a government initiative designed to promote the country as a retirement haven for affluent foreigners. Though started in 2002, it was more of a rebranding exercise following previous efforts. Prior to 2002, it was aptly known as the Silver Hair Program (SHP). The exact date of its inception remains unclear although there have been reports suggesting that it started in 1987 (Edwards 2001; Chan 2004). The Malaysian Ministry of Tourism and Culture's (MOTAC) earliest available data on successful applicants dates back to 1996 and this has often been used by researchers as the date of inception. As MOTAC only took over the handling of the MM2H from the Immigration Department (ID) of the Ministry of Home Affairs (MHA) in June of 2006, it is neither aware of the existence of a policy paper on the SHP nor able to confirm the actual date of commencement. Therefore, the year 1996 may mark the first availability of statistical data but it does not necessarily represent the initiation of the SHP.

What is evident is that the SHP was initially formed to target senior citizens of a specific group of countries, i.e., the United Kingdom and Japan, apart from a few other Western European nations. These were countries that Malaysia has close historical and economic ties with. The LEP further provided the motivation in the case of Japan. It marked Malaysia's interest in international retirement migration and intention to help ease restrictions for financially independent foreign retirees to move into and experience the country's diverse cultures, and to contribute to the local economy and community development in the process.

Several provisions were introduced under the SHP. Applicants must be 55 years old and above, which were considered as retirees and semi-retirees. They were not allowed to work and were required to open a bank deposit account of RM100,000 for singles and RM150,000 for couples upon approval of their application. Successful applicants were required to show proof of their monthly pension incomes of RM7,000 (for singles) or RM10,000 (for couples) and would only be allowed to stay for a maximum period of 15 years. Subsequently, several minor changes were introduced to appease calls from interested foreigners who saw the provisions as restrictive. The age limit was lowered to 50 years and limitations to the length of stay were removed. In 1999, nationality restrictions were lifted, allowing applications from nontargeted countries.

Based on the availability of data from 1996 to 2001 (see Table 3), only a total of 828 principal participants were approved under the SHP, of which the 
Japanese participants made up a mere 9.5 percent. One of the main problems was the lack of promotion and marketing of the program abroad. To create more awareness and increase promotional efforts, the ID encouraged private companies, particularly those involved in property development, to participate in supporting and sponsoring the program. The Country Heights Quality Life Services (CHQLS), a subsidiary company of Country Heights Holdings Berhad, was one of several companies involved. In June 2000, the CHQLS took up the idea and set an ambitious target to bring in 20,000 participants in 3 years as well as to spend RM20 million "on promotional and marketing activities worldwide" (Travel Weekly 2000). ${ }^{5}$ Although the targeted figure was not achieved, there were an expanded participation from other countries such as Taiwan, Hong Kong, Singapore and Indonesia. ${ }^{6}$

Table 3: Participants under the Silver Hair Program.

\begin{tabular}{|c|c|c|c|c|c|c|c|c|c|}
\hline \multirow{2}{*}{ No } & \multirow{2}{*}{ Country } & \multicolumn{6}{|c|}{ Year } & \multirow{2}{*}{ Total } & \multirow{2}{*}{$(\%)$} \\
\hline & & 1996 & 1997 & 1998 & 1999 & 2000 & 2001 & & \\
\hline 1 & $\begin{array}{l}\text { United } \\
\text { Kingdom }\end{array}$ & 5 & 9 & 15 & 49 & 40 & 46 & 164 & (19.8) \\
\hline 2 & Singapore & - & - & - & 38 & 38 & 42 & 118 & (14.3) \\
\hline 3 & Taiwan & - & - & - & 32 & 32 & 35 & 99 & (12.0) \\
\hline 4 & Japan & - & 3 & 4 & 26 & 26 & 20 & 79 & $(9.5)$ \\
\hline 5 & China (PRC) & - & - & - & 4 & 19 & 24 & 47 & $(5.7)$ \\
\hline 6 & Indonesia & - & - & - & 8 & 20 & 17 & 45 & $(5.4)$ \\
\hline 7 & India & - & - & - & 2 & 4 & 18 & 24 & $(2.9)$ \\
\hline 8 & Pakistan & - & - & - & 3 & 3 & 1 & 7 & $(0.8)$ \\
\hline 9 & South Korea & - & - & - & 2 & 2 & 1 & 5 & $(0.6)$ \\
\hline 10 & Others & 2 & 6 & 4 & 59 & 73 & 96 & 240 & $(29.0)$ \\
\hline \multicolumn{2}{|c|}{ Total } & 7 & 18 & 23 & 223 & 257 & 300 & 828 & (100) \\
\hline
\end{tabular}

Note: Figures are of principal participants (exclude spouses and dependents).

Source: MOTAC website.

More gradual changes were introduced to the program. The ruling on yearly renewal of social pass and visa, for example, was relaxed in December 2001 by allowing participants to obtain a 3-year visa instead (Edwards 2001). In 2002, the SHP was improved and rebranded as the MM2H. Instead of limiting the program to only the retirees, the ID decided to introduce two age categoriesone for those 50 years and above and the other for those between 18 and 49 years. The former is meant for retirees similar to the SHP while the latter is a new initiative meant to fulfil the growing demands of younger individuals who 
were still employed but wanted to make Malaysia their vacation home. The gap between the former and the latter is tapering with the former constituting 56 percent while the latter at 44 percent, suggesting that the MM2H no longer remains largely a retirement program. ${ }^{7}$

In April 2006, a string of new benefits was announced by the Malaysian government. Successful applicants would enjoy a 10 -year social visit pass and multiple-entry visa and be guaranteed renewal for another 10 years if they do not violate the Malaysian laws. This relaxation of immigration rules gives tremendous mobility to participants to freely travel in and out of the country. They will have the chance to make Malaysia their home base and travel around the region with ease. Participants are also entitled to 80 percent housing loan for the purchase of residential properties and can do so without approval from the Foreign Investment Committee. As icing on the cake, they are allowed to bring in a maid from their home country, obtain student passes for their school-going children to study at local universities, and ship their own cars over or purchase locally assembled ones free of import and excise duties. The latter point is an irresistible incentive that Malaysians could only dream of as it will translate to a 35 percent saving of the market value.

Despite enhanced incentives, the ruling barring participants from working or earning an income had remained. By the end of 2008, the number of participants has swelled to over 12,000 and there was a growing call for more flexibility primarily on the permission to work. The ID issued a circular in February 2009 with new inducements:

1. Participants aged 50 and above are allowed to work not more than 20 hours per week but they must possess specialised skills and expertise that are required in the critical sectors of the economy.

2. Participants of all ages can invest and participate in business, subject to existing government policies, regulations and guidelines.

3. Foreign spouses of Malaysian nationals can choose either to participate in the normal Spouse Program or apply for the MM2H.

4. The 10-year social visit pass will be extended to participants under the SHP and MM2H prior to April 2006.

5. Employment pass holders are exempted from the "cooling off period" but must apply for the MM2H program 3 months before expiration of their passes.

6. Participants will receive identification cards with permanent address in Malaysia that can be validated from the tenancy or sales and purchase agreement.

7. The age limit of unmarried dependent children is raised from 18 years to 21 years. ${ }^{8}$ 


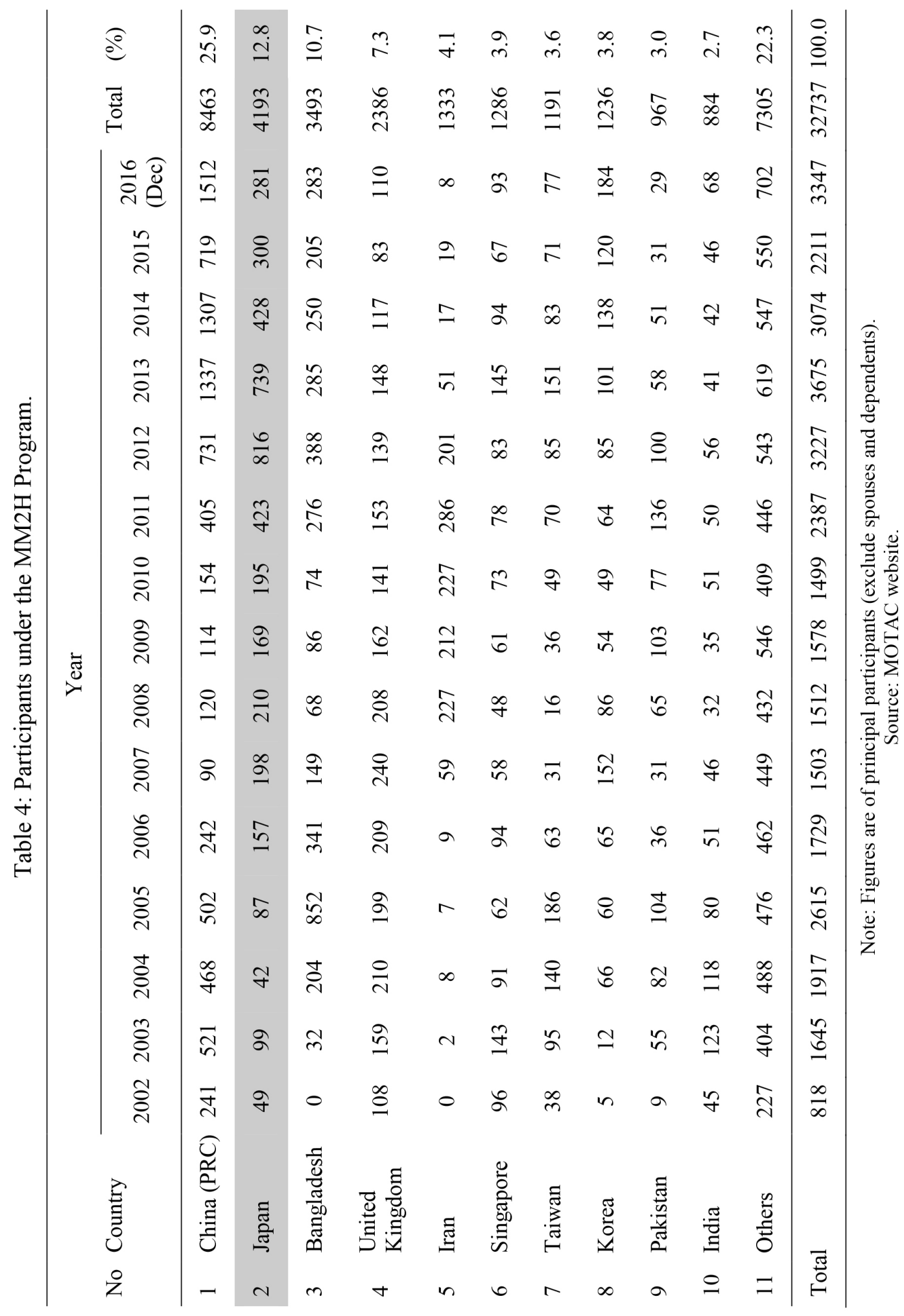


A total of 32,737 principal participants have been recorded from 1996 to December 2016. As Table 4 indicates, Japan features very strongly among the top countries contributing to the MM2H program with 12.8 percent, ranking second behind China. From 2006 to 2012, Japan topped the list with a total of 2,168 participants compared to China $(1,856)$ and Bangladesh $(1,382)$ before being overwhelmed again by China.

Compared to the SHP, the MM2H program has gone through numerous improvements and streamlining particularly in the past several years since being taken over by MOTAC. In offering a more comprehensive approach to the program, MOTAC created a One-Stop Center (OSC). The aim was to provide better integrated services by centralising all relevant information pertaining to the $\mathrm{MM} 2 \mathrm{H}$ and having an in-house immigration unit. The need for an OSC partly came from the demand of applicants as well as agents to have access to the necessary procedural guidelines and benefits under a single package. It is thus intended to speed up the approval process and to also serve as a dedicated point of reference for individuals interested in applying directly to MOTAC. However, there were hiccups in the implementation process due to a number of factors such as the lack of funding for the MM2H program, the small workforce entrusted to manage the program, the lack of coordination among the different ministries and governmental departments, and the unstable policy guidelines that confuses applicants and agencies at times.

The role of agents was important in helping to promote the program. Initially, the government was dependent on appointed agents from the private sector and individuals to promote, market and sponsor prospective applicants. Some property developers took up the opportunity of becoming agents as a way to market their high-end properties to prospective foreign buyers. Due to the lack of regulation, new agencies mushroomed to take advantage of the demand as the news of the MM2H spread and the program became more popular with foreigners. Issues related to unclear visa procedures and concerns with unscrupulous agents inevitably arose. In June 2007, better regulations were put in place whereby all applications must be submitted through licensed MM2H agents. Non-licensed agents were given time to apply for their licenses which is renewable annually. This was seen as a step forward as it helped to reduce unscrupulous agents who were out to make a quick profit and prevent the reputation of the country from being jeopardised. ${ }^{9}$ In January 2009, MOTAC went a step further by allowing direct application to the dismay of some of the licensed agents. While such an option can help applicants to save on agent fees, most Japanese applicants continue to depend on agents due to their lack of fluency in English. 
Moving the program from the MHA to MOTAC has further signified the government's commitment in ensuring the sustainability of the program. Compared with the former which is primarily concerned with national security and safety issues, the latter is better suited to employ a more holistic approach that can link the needs of the program to the various sectors of the tourism industry and property markets apart from engaging in overseas promotional activities like expositions and roadshows. MOTAC's expertise in the business of hospitality could well enhance the program in economic terms. Nevertheless, the MHA remains the final decision maker of the application process. Apart from the compulsory letter of good conduct requirement, applicant's data are screened by the ID and the Royal Malaysian Police for any security violations. If in the past the MM2H Approving Committee consists of MOTAC officers and chaired by the Deputy Director General of the ID on a monthly basis to evaluate and approve applications, it is now chaired by the Deputy Secretary General of MOTAC on a weekly basis. During the meeting, decisions on whether to approve the applications are taken including comments on security considerations if any and will then be forwarded to the Director General of ID for endorsement. The latter reserves the right to reject any applications should new evidences of security violations were to be found, for example.

In addition, the MHA plays a pivotal role in matters pertaining to the decision on relaxation of conditions for visa approval. Policy matters including the terms and conditions of the program are solely within the jurisdiction of the MHA. Despite the existing benefits that have included the allocation for bringing in pets, applicants have continued to request for greater flexibilities especially in allowing them to work full time instead of the 20 hours per week restriction and on loosening the financial criteria. ${ }^{10}$ Comparably, the financial requirements for applicants below 50 years of age are more stringent than for those aged 50 and above because of the higher probability of having dependent children. ${ }^{11}$

While simplifying the process will most likely increase the number of participants, the MHA will need to assess and consider the negative implications that further relaxation may have on local employment and on the issue of attracting the right candidates. As Carrie Chan wrote, “... with its low financial threshold of US\$26,300 (HK\$210,000), the program seems designed to whet the appetite of corrupt bureaucrats wanting to leave China with their swollen pockets intact" (2004). China, Iran and Bangladesh are among the top five countries participating in the program although they were not originally the main targets for the MM2H scheme (see Table 4). With the program covering a wide-range of age groups, the MHA and the police force 
are wary of syndicates that may try to abuse the scheme by gaining easier access into the country to set up illegal businesses or distribute contrabands that could potentially add to the social woes of the country. There is now an indication by MOTAC that it will raise the financial requirements, especially on the fixed deposit amount, to attract good quality candidates (Lum 2017).

\section{JAPANESE RETIREES IN PENANG UNDER THE MM2H PROGRAM}

Japanese retirees interested in building their second lives abroad would normally receive information from television documentaries and travel guidebooks from their home country. While documentaries provide the images and understanding of how living abroad can be imagined, quarterly magazines like Rashin and Longstay and travel books like Chikyu no Kurashikata (Global Residents' Travel Guide) provide the needed information to plan their journey (Ono 2008: 153-154). The Longstay magazine, published by the LSF, enables prospective applicants to receive up-to-date information in their own language and reduces surprises by preparing them for what to expect when they travel abroad. For those who are internet savvy, they will also be able to search and learn from other people's experience through blogs written by individuals who may have participated in the MM2H program.

If such information is insufficient, prospective individuals can enrol themselves in seminars held regularly by the LSF in cooperation with the Japanese Ministry of Tourism. Interested individuals can also participate in yearly $\mathrm{MM} 2 \mathrm{H}$ roadshows organised in part by the Malaysia Tourism Promotion Board (popularly known as Tourism Malaysia) and participated by MM2H agencies in several key cities such as Sapporo, Niigata, Kyoto and Osaka. These events will not only help them to make informed decisions from the myriad options laid before them but opportunities to discuss directly with $\mathrm{MM} 2 \mathrm{H}$ agents on procedural and documentation matters to ensure a smooth application process.

Interestingly, not everyone finds the seminars and roadshows helpful. Some found them to be too costly and not necessarily beneficial. Instead of becoming too dependent on third party information, they prefer to experience firsthand by visiting and staying at a hotel in Penang, for example, for a few weeks not as a tourist but as a longstayer mingling with the locals. They may then move to another city, Ipoh or Kuala Lumpur for example, or to a neighbouring country and repeat the same process. They are individuals who are more adventurous and who believe that experiencing it firsthand is better 
than being informed by others. Once decided, they would then return to Japan, prepare their documents and start their application process.

\section{Why Penang?}

There are obviously various reasons for Japanese retirees to consider Penang as their second home. The three most important ones are warm weather, lower cost of living and safe environment. The balmy and sunny weather condition with stable temperatures throughout the year is of outmost importance especially for those who hail from colder climates in Japan such as Hokkaido and the Tohoku region. Some of the Japanese retirees have reported that they have found respite from joint pains, allergies and high blood pressures after moving to Penang, believing that the illnesses were caused by the harsh volatile weather and seasonal changes at home. For some others, it was simply to get away from the coldness as their body become less and less tolerable to freezing temperatures (MM2H participants, personal comm. June 2011).

Cost of living is another major factor since most of the participants are retirees and are fully dependent on their monthly pensions. Penang, despite high property prices, is relatively cheaper compared to Kuala Lumpur, Selangor and Sabah. Numerous hawker centres are spread across the island and the number of Japanese restaurants and upscale supermarkets selling Japanese products have increased in recent years. Being an island, amenities are in close proximity and are easily accessible through local transportation, i.e., public buses and taxis. This means that not only would they have the independence and freedom to move freely but could do so without becoming too fatigue due to long travel time. The high level of development and the compactness of Penang allow pensioners the opportunity to enhance their value for money in maintaining their economic lifestyles. Unlike foreign economic migrants, these retirees do have the luxury to choose places of their choice and many find Penang a place where they can double their "money power" to maintain decent quality living compared to their homes (MM2H agent, personal comm. May 2011).

A safe environment plays a major role in attracting Japanese retirees to Penang. Penang's crime index has been in steady decline for the past few years and is relatively lower than most major cities in Malaysia. "Safe," however, does not merely refer to crime but also to the absence of natural disasters such as earthquakes, flooding and tsunamis, and social unrests such as street riots as observed in neighbouring countries like Thailand. Furthermore, there are no strong anti-foreigner sentiments in Penang that could possibly threaten their 
safety. Penang has been historically accommodating to all types of foreigners since its inception in 1786.

Other reasons for considering Penang are its closeness to Japan compared to Europe since the ability to return home quickly due to an emergency is an important factor for some, its friendly and hospitable people, its range of food from street hawkers to high class restaurants, its top-notch hospitals and medical facilities, the presence of a Japanese community and being less cosmopolitan than Kuala Lumpur.

The growing ageing population in Japan will undoubtedly continue to serve as the source to fuel the MM2H program. More importantly, structural changes of Japanese families where elderly couples are increasingly being separated from their children and could no longer depend on their pensions to support their comfortable lives at home, and demographic changes with an increase in the number of singles and small family size that makes migration after retirement easier, as well as the need for affordable but quality care are seen as push factors encouraging elderly Japanese to leave their homes in search of a more rewarding second life abroad (Toyota and Ono 2012).

\section{Social Networks and Support Systems}

For any individuals who plan to stay abroad over an extended period of time, a network of support and social connection becomes highly essential. More so for elderly people who may feel lonely, isolated and even depressed due to language barrier and being in an unfamiliar surrounding far from home. Penang, and Malaysia in general, are made up of three major races (Malay, Chinese and Indian) and those who are conversant in Japanese are extremely small or close to none. So, who do the Japanese retirees turn to when they need to call for a plumber or an electrician? Who helps them communicate with doctors in a hospital when they are in pain? How do they build relationships with the local community?

Since most of the Japanese participants in Penang, at least those interviewed, ${ }^{12}$ have not worked or lived in Penang prior to participating in the $\mathrm{MM} 2 \mathrm{H}$ program, they do not have any previous knowledge or experiences that they could rely on to help them settle down. A multitude of support groups are therefore required. They could be made up of government agencies, MM2H agents, clubs, associations, neighbours, hobbyists, friends and acquaintances. In Penang, some MM2H agents play multiple roles such as offering housing services to their clients by partnering with local real estate agencies. The agent acts as the middle person and interpreter and ensures that all the necessary 
paperwork is completed accordingly. The same agent can at times be requested by the retirees for help in recommending plumbers, electricians and interior designers for their homes, and even to accompany them to hospitals. They are initially dependent on their agents but as their social circles enlarge and support system develops, they become more independent and less reliant on the need for advices and suggestions from their agents. Certain private hospitals in Penang are aware of the growing number of Japanese retirees under the MM2H program and have taken proactive steps to hire Japanese speaking assistants and nurses to ensure smoother communication between the doctors and their Japanese patients, effectively reducing the role of MM2H agents as interpreters.

Another enticing fact about Penang is the presence of the Penang Japanese Association (PJA), which was formed in 1977. As an established club exclusively for the Japanese people in Penang, it serves as a support mechanism for the Japanese community and creates closer bonding through the organising of various events. Regular activities enable members to gather and exchange information not only about their lives in Penang but also about situations in their home country. Some Japanese retirees may find it more meaningful to form a small group among themselves and, for example, gather at a trendy café a few times a week to chat over morning coffee. Others may choose to volunteer themselves at social clubs set up by MM2H agents where retirees can organise weekly activities either among themselves or with the participation of locals. The activities could include travel tours, ikebana (flower arrangement), shodo (calligraphy), tea ceremony, Japanese drums and Japanese language. Keeping in touch with their own community is deemed as necessary in order to keep abreast of the latest news and to be aware of policy changes in the MM2H program specifically and the Japan-Malaysia relations generally that could have an effect on their situation (MM2H participant, personal communication, June 2011).

Depending on the interest of the retirees, local groupings such as golf clubs and Buddhist associations provide opportunities for them to meet local people and engage in stimulating exchanges. It also helps them build and expand their network of friends and even engage in passionate relationships through shared interests. The friendship between the retirees and locals are never clear. Although involvement in local associations can enrich the retirees' socialisation process by keeping them active, language difficulties can form the barrier that limits the process. Thus, while some of them view exchanges with local communities positively, they find it hard to maintain a robust sustainable relationship (MM2H participants, personal comm. June 
2011). The 2011 Tohoku earthquake and tsunami, however, has arguably created a greater amity between the Japanese community and the local people of Penang when many Penangites who were shocked with the magnitude of the calamity came out in strong support of the numerous fundraising events held throughout Penang.

How well the retirees are able to enjoy their new lives is predicated on their ability to assimilate effectually into the local culture, which is in a way dependent on their individual outlook on - and experiences - in life. The Japanese equivalent of the English saying of "when in Rome, do as the Romans do" is gō-ni itte-wa gō-ni shitagae (郷に入っては郷に従え) and this raises the question of how prepared are they to change and adapt by accepting certain norms and practices of the local community. Punctuality, for example, is a non-issue in Japan but it can be in Penang since being late for several minutes is considered an acceptable norm. Public buses rarely arrive on time. Malaysian motorists have also been known for their disregard of pedestrians' safety. Retirees who are exceptionally particular of their food such as the quality of water used in preparing rice could encounter a less pleasant experience. Similarly, those who have bad experiences such as an encounter with theft or quarrels with neighbours may end up leaving the program sooner than expected.

\section{Evaluating the MM2H Program and the Japanese Contribution}

One measurement of success of the MM2H program is its ability to attract participants from two targeted countries-Japan and the United Kingdom. Twenty years after its initiation, these two countries remained among the top five countries in the program, with a total share of 12.8 percent and 7.3 percent respectively (see Table 4). Participation from non-targeted countries such as China, Bangladesh, Iran, Singapore, South Korea, Taiwan, Pakistan and India further strengthens the notion that the program is attractive to other nationalities as well. The success of the program is tied to the good perception that the country enjoys as a retirement haven for foreign retirees. This good perception has been steadily built through multiple platforms from the role played by Tourism Malaysia in promoting the country abroad to cooperative institutions like the LSF, travel agencies, documentaries, print media, online rankings, blogs and the word of mouth. The LSF's annual surveys (see Table 2) clearly demonstrate the continuous strength of Malaysia as the country of choice for Japanese retirees. The MM2H program and its incentives may not 
be the ultimate reason for the influx of longstayers but its presence helps to remove institutional barriers and facilitate retirement migration in Malaysia.

Another aspect that reflects positively on the program is in the area of foreign capital acquisition. With each Japanese participant requiring to maintain RM100,000 in fixed deposit for those aged 50 years and above throughout their stay, and assuming that all the 4,193 participants from year 2002 until December 2016 (see Table 4) are aged 50 years and above, they would have contributed to a capital inflow of RM419.3 million (USD95.3 million). Assuming the same but factoring in the total number of participants of 32,737 people (see Table 4), the total amount would have reached RM3.2 billion (USD727.1 million). Despite that, several questions remain. Out of 4,193 participants, how many continue to participate in the program and how many have opted out? Among those who still remain, how many are inside the country and how many have left and perhaps joined retirement schemes in other countries?

Tracking the whereabouts of the participants remains a big challenge since there is no travel restrictions imposed on them. A review of the MM2H scheme carried out by the then Penang based Socio-economic and Environmental Research Institute (now renamed as the Penang Institute) in 2008 found that while many procedural requirements have been relaxed, an "information-storing and tracking system" is needed to enhance collaboration particularly between government agencies and private enterprises and to keep track of the participants' whereabouts (SERI 2008: 7). Some retirees may choose to settle down in a single place and assimilate themselves into the local community while others may use Penang as their base to either visit other destinations in Malaysia or travel to neighbouring countries by taking advantage of the cheap airfares. Some may have left for home but continues to hold on to their visas. As such, MOTAC only has records of those who have terminated their participation or when their visa period ends naturally.

Furthermore, it would be difficult to assess the contributions of the Japanese participants to the Malaysian economy without a clear idea of their movements. The program may be viewed as a visa approval process but its significance lies in the economic contributions of the retirees. Incentives on car and home purchases are meant to encourage spending. Likewise, paying rentals, food, shopping and travelling contribute to generating income and jobs for local residents. ${ }^{13}$ These are important contributions apart from nonmonetary ones such as the sharing of their knowledge and expertise with the local community. Since 2007, MOTAC has kept a record of the addresses of $\mathrm{MM} 2 \mathrm{H}$ participants based on their residential property sales and purchase 
agreements. This obviously only pertains to those who have bought properties and not those who chose to rent.

An area of contribution that is often overlooked is medical tourism. As elderly people, there are plenty of chances for them to contribute to the development of Penang as a medical tourist destination. Japan, Indonesia and Singapore are considered to be the three largest groups of medical tourists in Penang (Liew and Lim 2015). The relatively high cost of healthcare in Japan is a push factor for the elderly Japanese to look abroad for treatment. But unlike Indonesians who may seek treatment in Penang due to the lack of medical facilities in their home country, healthcare services in Japan are much more developed. In other words, Japanese elders would be more familiar and comfortable with the healthcare culture in Japan than in Malaysia. It is thus not surprising that unfamiliarity with Malaysian healthcare practices and language barrier remain a major challenge for them (see Kohno et al. 2016). Hence, promoting Malaysia as having "advanced medical facilities" alone may be insufficient in wooing Japanese retirees to fully utilise the healthcare services in the country without offering a more conducive environment where they could identify with the healthcare support system and communicate clearly with local doctors and nurses.

In Penang, a few private medical centres and hospitals have resorted to the hiring of Japanese speaking interpreters to assist Japanese patients. This may help alleviate patients' anxiety and is a positive development that can further bolster the promotion of the MM2H program in Japan. There are obviously opportunities for close collaboration between the program and the healthcare industry. One participant suggested that an old folks home for the Japanese be set up in Penang and urged MOTAC to consider a specialised medical insurance package for those aged 50 years and above as a further incentive under the program (MM2H participant, personal comm. October 2011). ${ }^{15}$ The main objective is not only to provide participants with visas for long term stay but to retain them in the country for a longer period. The longer they stay the more they will be able to contribute economically and socially.

Incentives offered under the $\mathrm{MM} 2 \mathrm{H}$ program are certainly not without concerns. While car purchase incentive for program participants seems to be a non-issue, providing $\mathrm{MM} 2 \mathrm{H}$ participants with the opportunity to own properties has not been well received by some Malaysians who viewed the scheme as an easy way for foreigners to purchase properties and cause the house prices to escalate rapidly. The real estate sector in Malaysia is viewed favourably compared to other countries such as Thailand because foreigners 
are allowed to own land. The top three preferred locations for property purchase were Penang, Kuala Lumpur and Selangor. ${ }^{15}$

In Penang Island where land is considered scarce, property prices have increased tremendously in the past five years. Housing developers were accused of building too many luxury homes catering to wealthy individuals and not to low- and middle-incomers who were no longer capable of owning landed properties, driving many to purchase their homes on the mainland. Since land matters are within the purview of individual state governments, there have been calls for states to set higher minimum purchase prices for foreigners to prevent them from competing directly with Malaysians in the property market.

Nevertheless, there have been no clear supporting evidences that foreigners investing in high-end residential properties were the cause of overall skyrocketing property prices. To what extend finger-pointed foreigners are $\mathrm{MM} 2 \mathrm{H}$ participants are even less clear due to the lack of data and the fact that there are hardly any property development projects that is specifically catered to the needs of the MM2H buyers (SERI 2008: 5-6). In fact, interviews conducted with Japanese participants indicate that most do not have the intention to purchase properties to live or for the purpose of making a profit, preferring instead to rent. ${ }^{16}$ This allows them to enjoy their lives in a carefree manner since owning a property is seen as too cumbersome and restrictive. One key advantage of renting is the ability to move to a different location easily should the need arises or when there are unavoidable problems with neighbours.

\section{CONCLUSION}

The MM2H program has undergone a series of structural improvements to support Malaysia's aim of becoming a sought-after destination for foreigners to retire and call it their second home. Consistency in new entries into the program testifies to the popular interest shown towards the program and the country. The next step is to enhance the monitoring capabilities and devise new strategies including cooperation with various sectors of the economy to provide a more rounded experience for the participants and keep them in the country for longer periods of time. It is thus necessary to identify and be attentive to the various needs of the participants. The Japanese retirees in Penang appear to prioritise less on big item purchases such as cars and homes and more on the conveniences and choices that Penang is able to offer them. 
This include the widely availability of food, outlets, ample sunshine, public transportation and flight options as well as the unique social composition of warm and friendly locals and a relatively safe environment.

\section{NOTES}

* Benny Teh Cheng Guan is an associate professor at the School of Social Sciences, Universiti Sains Malaysia (USM), Penang. His research interests include East Asian regionalism, ASEAN community building, traditional security, human security and the politics of free trade agreements. He is the editor of Foreign Policy and Security in an Asian Century: Threats, Strategies and Policy Choices (World Scientific, 2014) and Human Security: Securing East Asia's Future (Springer, 2012).

1 The top five cities are all in developed nations, namely Austria, Switzerland, New Zealand, Germany and Canada. Kuala Lumpur is ranked in at 86th.

2 The other countries were Canada (818), Spain (439), Philippines (406), Indonesia (401) and United States (281).

3 The Japanese community converged around Cintra Street (and Kampung Malabar), a red light district known to locals as the Jipun Kay (Little Japan Street). The karayukisans (Japanese prostitutes) mainly came from impoverished regions of Kyushu in search of a better life (Liang 2002: 3). Out of 207 Japanese residing in Penang in 1910, 149 were females (out of which 126 were prostitutes) and 58 males (ibid: 2).

4 The Look East Policy was an initiative by then Prime Minister Mahathir Mohamad for Malaysia to learn from the industrialisation experiences and work ethics of Japan (and South Korea).

5 The parent company, Country Heights Holdings Berhad, has set up a subsidiary company called Mines Express (MM2H) Sdn Bhd and is therefore still involved in the retirement program but no longer carry out heavy promotional activities.

6 For Hong Kong, there was a recorded figure of 29 participants (3.5 percent) for the period 1996-2001. Despite the lifting of restrictions on nationality, Japan, the United Kingdom and Western European countries continued to remain the main target groups.

7 The data are for the period from 2007 to 2015. The narrowing of the gap is clear when compared to the statistics for the period from 2007 to May 2011 with 67.4 percent for 50 years and above and 32.6 percent for below 50 years of age (MOTAC official, personal communication, May 2011).

8 The term "dependent" is broadened to include unmarried children aged 21 years and below, step-children, disabled children and parents.

9 To weed out problematic agents, they must first fulfill the minimum requirement of submitting $10 \mathrm{MM} 2 \mathrm{H}$ applications in a year in order to have their license renewed for the following year.

10 It would be unlikely for the MHA to allow full time work since it would not only require a working permit but the program itself is not designed to support economic migrants.

11 To qualify, younger applicants need to show proof of liquid assets worth at least RM500,000 and an offshore income of RM10,000 per month. Once approved, they 
will need to open a fixed deposit account of RM300,000 but are allowed to use half of the amount after a year for house purchase, children education and medical expenses. For the older group category, it is RM350,000 of liquid assets and an offshore income of RM10,000 per month but upon approval can either choose to open a fixed deposit account of RM150,000 and withdraw up to RM50,000 in the second year or show proof of a pension scheme of at least RM10,000 per month (usually government pension) approved by the MM2H program (MOTAC website).

12 About 10 in-depth interviews were carried out with Japanese participants and MM2H agents.

13 A recent study suggests that retirees under the MM2H program spend on average RM6,030 (USD1,370) per month. This figure however covers multiple nationalities. There was no specific breakdown of monthly expenditure based on nationality (Wong and Musa 2017).

14 Approved MM2H participants must hold medical insurance coverage but exemptions are given to those who are ineligible due to their age or certain medical history.

15 In 2011, the preferred locations based on the numbers of property purchased were Kuala Lumpur (52.5 percent), Selangor (20.3 percent), Penang (15.1 percent), Johor (5.07 percent), Sabah (1.94 percent) and others (5.09 percent) (MOTAC official, personal communication, May 2011).

16 This seems to be generally the case. Wong and Musa (2017) found from their survey of $504 \mathrm{MM} 2 \mathrm{H}$ international retirees that over 70 percent of them stay in rented properties.

\section{REFERENCES}

Castles, S. 2002. Migration and community formation under conditions of globalization. International Migration Review 36 (4): 1143-1168, https://doi. org/10.1111/j.1747-7379.2002.tb00121.x.

Chan, C. 2004. Malaysia beckons foreign retirees. Asia Times Online, 10 April. http://www. atimes.com/atimes/Southeast_Asia/FD10Ae04.html (accessed 23 March 2011).

Cook, I. and P. Crang. 1996. The world on a plate: Culinary culture, displacement and geographical knowledges. Journal of Material Culture 1 (2): 131-153, https://doi. org/10.1177/135918359600100201.

Country Heights to manage Malaysia's Silver Haired. 2000. Travel Weekly, 29 June. http:// demo.travelweeklyweb.com/article/country_heights_to_manage_malaysia_s_ silver_haired.html (accessed 23 March 2011).

ECA International. 2015. Singapore is among world's top 20 most expensive cities for expatriates. http://www.eca-international.com/news/press_releases/8192/ Singapore_is_among_world_s_top_20_most_expensive_cities_for_expatriates\#. VrBaNZp95pg (accessed 31 January 2016).

Edwards, A. 2001. Boon to foreign retirees. The Star, 4 December.

Fechter, A-M. 2007. Transnational lives: Expatriates in Indonesia. Hampshire: Ashgate. 
Fountain, J. and C. M. Hall. 2002. The impact of lifestyle migration on rural communities: A case study of Akaroa, New Zealand. In Tourism and migration: New relationships between production and consumption, ed. Hall, C. M. and Williams, A. M., 153168. Dordrecht: Kluwer Academic Publishers, https://doi.org/10.1007/978-94-0173554-4_8.

Friedman, J. 1995. Global system, globalization and the parameters of modernity. In Global modernities, ed. Featherstone, M., Lash, S. and Robertson, R., 69-90. London: Sage, https://doi.org/10.4135/9781446250563.n4.

Gurran, N. 2008. The turning tide: Amenity migration in coastal Australia. International Planning Studies 13 (4): 391-414, https://doi.org/10.1080/13563470802519055.

Haas, W. H., III and Serow, W. J. 1993. Amenity retirement migration process: A model and preliminary evidence. The Gerontologist 33 (2): 212-220, https://doi.org/10.1093/ geront/33.2.212.

Hannerz, U. 1992. Cultural complexity. New York: Columbia University Press.

Hongsranagon, P. 2005. Activities arrangement in Chiangmai province for long stay Japanese pensioner tourists. Journal of Demography 21 (2): 85-98. . 2006. Information provision - One more necessity for long stay tourism of Japanese pensioners in Chiangmai. Journal of Population and Social Studies 14 (2): 101-109.

International Living. 2010. International Living's global retirement index: The best places in the world to retire in 2010. http://internationalliving.com/2010/08/retirementindex-2010/ (accessed 29 January 2016).

.2011. The scores and how our 2012 retirementindex works. http://internationalliving. com/2011/12/the-scores-and-how-our-2012-retirement-index-works/ (accessed 29 January 2016).

. 2016. The world's best places to retire in 2016. http://internationalliving. com/2016/01/the-best-places-to-retire-2016/ (accessed 31 January 2016).

King, R., Warnes, T. and Williams, A. 2000. Sunset lives: British retirement migration to the Mediterranean. Oxford: Berg.

Kohno, A. et al. 2016. Factors affecting Japanese retirees' healthcare service utilisation in Malaysia: A qualitative study. BMJ Open 6 (3): 1-8, https://doi.org/10.1136/ bmjopen-2015-010668.

Liang, C. 2002. The prewar Japanese community in Penang during the period $1880-1940$. The Penang Story - International Conference, The City Bayview Hotel, Penang, Malaysia. 18-21 April.

Liew, D. and Lim, C. H. 2015. Medical tourism: A billion-ringgit industry for Penang. Penang Monthly 10 (15): 40-43.

Live and Invest Overseas names the world's top 21 retirement havens. 2013. The Huffington Post, 19 August. http://www.huffingtonpost.com/kathleen-peddicord/live-andinvest-overseas-_b_3461348.html (accessed 31 January 2016).

Loh, W. L. 2009. Penang's trade and shipping in the imperial age. In Penang and its region: The story of an Asian entrepot, ed. Yeoh, S. G. et. al., 83-102. Singapore: NUS Press.

Longino, C. F. and Smith, K. J. 1991. Black retirement migration in the United States. Journal of Gerontology 46 (3): S125-S132, https://doi.org/10.1093/geronj/46.3.S125. 
Long Stay Foundation (LSF). 2009. Long stay statistical survey. http://www.longstay.or.jp/ uploads/photos1/448.pdf (accessed 31 January 2016).

Lum, K. K. 2017. Ministry mulls measures to strengthen MM2H programme. The Edge Property, 27 March. http://www.theedgeproperty.com.my/content/1104265/ ministry-mulls-measures-strengthen-mm2h-programme (accessed 20 April 2017).

Malaysia one of top 18 best places to retire. 2012. New Straits Times, 28 March. http:// www.nst.com.my/nation/general/malaysia-one-of-top-18-best-places-to-retire1.66991?localLinksEnabled=false (accessed 2 April 2012).

Mercer. 2016. 2016 Quality of living worldwide city rankings - Mercer survey. https:// www.imercer.com/content/mobility/quality-of-living-city-rankings.html\#list (accessed 21 November 2016).

Ministry of Tourism and Culture (MOTA). n. d. http://www.mm2h.gov.my (accessed 20 January 2017).

More retirees choose Penang. 2006. The Star, 2 March. http://thestar.com.my/news/story. asp?file $=/ 2006 / 3 / 2 /$ north $/ 13535092 \&$ sec $=$ North $($ accessed 25 March 2011).

Murakami, K., Gilroy, R. and Atterton, J. 2009. Planning for the ageing countryside: The potential impact of multi-habitation. Planning Practice and Research 24 (3): 285299, https://doi.org/10.1080/02697450903020734.

Nagatomo, J. 2009. Globalization, tourism development, and Japanese lifestyle migration to Australia. In Development in Asia: Interdisciplinary, post-neoliberal and transnational perspectives, ed. Nault, D. M., 215-236. Florida: Brown Walker Press.

O'Reilly, K. and Benson, M. 2009. Lifestyle migration: Escaping to the good life? In Lifestyle migration: Expectations, aspirations and experiences, ed. Benson, M. and O'Reilly, K., 1-14. Farnham, Surrey: Ashgate.

Ono, M. 2008. Long-stay tourism and international retirement migration: Japanese retirees in Malaysia. In Transnational migration in East Asia: Japan in a comparative focus, ed. Yamashita, S. et. al. Senri Ethnological Reports 77, 151-162. Osaka: National Museum of Ethnology.

Rodriguez, V., Fernandez-Mayoralas, G. and Rojo, F. 2004. International retirement migration: Retired Europeans living on the Costa Del Sol, Spain. Population Review 43 (1): 1-36, https://doi.org/10.1353/prv.2004.0009.

Rohlen, T. P. 2002. Cosmopolitan cities and nation states: Open economics, urban dynamics, and government in East Asia. Working paper, The Asia/Pacific Research Center, Stanford University. http://www.kas.de/upload/dokumente/megacities/ cosmopolitan.pdf (accessed 11 March 2012).

Sato, M. 2001. Farewell to Nippon: Japanese lifestyle migrants in Australia. Melbourne: Trans Pacific Press.

Socio-economic and Environmental Research Institute (SERI). 2008. Malaysia My Second Home (MM2H): A review of current implementation and growth potential. Penang Economic Monthly 10 (3): 1-8.

Shakuto-Neoh, S. 2014. Japan's elderly in Malaysia, like shooting stars in the twilight. East Asia Forum, 3 September.

Shimizu, H. 1993. The pattern of Japanese economic penetration of prewar Singapore and Malaya. In The Japanese in colonial Southeast Asia (Translation Series), ed. Shiraishi, S. S. and Shiraishi, T., 63-88. Ithaca: Cornell University. 
Toyota, M. and Ono, M. 2012. Building a temporary second home: Japanese long-stay retirees in Penang. In Catching the Wind: Penang in a Rising Asia, ed. Hutchinson, F. and Saravanamuttu, J., 160-178. Singapore: Institute of Southeast Asian Studies.

Wong, K. M. and Musa, G. 2014. Retirement motivation among 'Malaysia My Second Home' participants. Tourism Management 40: 141-154, https://doi.org/10.1016/j. tourman.2013.06.002.

Wong, K. M. and Musa, G. 2015. International second home retirement motives in Malaysia: Comparing British and Japanese retirees. Asia Pacific Journal of Tourism Research 20 (9): 1041-1062.

. 2017. Malaysia My Second Home (MM2H): Retirees' demographic profile and spending dynamics. Tourism Management 60: 42-46, https://doi.org/10.1016/j. tourman.2013.06.002.

Yuen, C. L. 1978. The Japanese community in Malaya before the Pacific War: Its genesis and growth. Journal of Southeast Asian Studies 9 (2): 163-179, https://doi.org/10.1017/ S0022463400009735. 